\title{
BIO-OPTICAL PROFILING FLOATS AS NEW OBSERVATIONAL TOOLS FOR BIOGEOCHEMICAL AND ECOSYSTEM STUDIES: POTENTIAL SYNERGIES WITH OCEAN COLOR REMOTE SENSING.
}

\author{
Hervé Claustre $^{(1)}$, Jim Bishop ${ }^{(2)}$, Emmanuel Boss ${ }^{(3)}$, Stewart Bernard ${ }^{(4)}$, Jean-François Berthon ${ }^{(5)}$, Christine \\ Coatanoan $^{(6)}$, Ken Johnson ${ }^{(7)}$ Aneesh Lotiker ${ }^{(8)}$, Osvaldo Ulloa ${ }^{(9)}$, Marie Jane Perry ${ }^{(10)}$, Fabrizio D'Ortenzio ${ }^{(1)}$, \\ Odile Hembise Fanton D'andon ${ }^{(11)}$, Julia Uitz ${ }^{(12)}$ \\ (1) CNRS (Centre National de la Recherche Scientifique) and Université P. \& M. Curie, Laboratoire d'Océanographie \\ de Villefranche, Chemin du Lazaret, 06230 Villefranche-sur-Mer, France, Email: herve.claustre@obs-vlfr.fr; \\ dortenzio@obs-vlfr.fr \\ (2) Earth Sciences Division, Lawrence Berkeley National Laboratory, One Cyclotron Road, M/S 90-1116, Berkeley, \\ CA 94720, USA, Email: jkbishop@lbl.gov \\ (3) University of Maine, School of Marine Science, 5741 Libby Hall Room 204A Orono, ME 04469-5741, USA, \\ Email:emmanuel.boss@maine.edu \\ (4) SIR - NRE (Council for Scientific and Industrial Research - Natural Resources and the Environment) Ecosystems \\ Earth Observation, 11 Jan Cilliers Street, Stellenbosch, South Africa, Email: SBernard@csir.co.za \\ (5) JRC (Joint Research Centre) - European Commission, Global Environment Monitoring Unit Institute for \\ Environment and Sustainability, Via Fermi, TP 272, 21027 Ispra, Italy, Email: jean-francois.berthon@jrc.ec.europa.eu \\ (6) Coriolis Data Center, IFREMER (French Institute for Exploitation of the Sea/Institut Français de Recherche pour \\ l'Exploitation de la Mer) DOP/DCB/IDM/SISMER (Informatique et données marines/Systèmes d'Informations \\ Scientifiques pour la Mer), Centre de Brest, BP 70, F-29280 Plouzané, France, \\ Email: Christine.Coatanoan@ifremer.fr \\ (7) Monterey Bay Aquarium Research Institute, 7700 Sandholdt Road Moss Landing, CA 95039, USA, \\ Email: johnson@mbari.org \\ ${ }^{(8)}$ Indian National Centre for Ocean Information Services (INCOIS), P.B. No. 21, Ocean Valley, Gajularamaram, \\ IDA Jeedimetla, Hyderabad 500 055, India, Email: aneesh@incois.gov.in \\ (9) Departamento de Oceanografía, Laboratorio de Procesos Oceanográficos y Clima (PROFC), Universidad de \\ Concepción, Cabina 7 - Barrio Universitario, Casilla 160-C, Concepción 3, Chile, Email: oulloa@profc.udec.cl \\ ${ }^{(10)}$ University of Maine, Darling Marine Center, School of Marine Science, 193 Clarks Cove Road, Walpole, \\ ME 04573 USA, Email: perrymj@maine.edu \\ ${ }^{(11)}$ ACRI-ST (Earth Observation - Environment), 260, route du Pin Montard - B.P. 234, 06904 Sophia Antipolis Cedex, \\ France, Email: oha@acri-st.fr \\ ${ }^{(12)}$ Scripps Institution of Oceanography, University of California San Diego, Spiess Hall 9500 Gilman Drive, La Jolla, \\ CA92093-0238,USA, juitz@ucsd.edu
}

\section{SUMMARY}

Profiling floats now represent a mature technology. In parallel with their emergence, the field of miniature, low power bio-optical and biogeochemical sensors is rapidly evolving. Over recent years, the bio-geochemical and bio-optical community has begun to benefit from the increase in observational capacities by developing profiling floats that allow the measurement of key biooptical variables and subsequent products of biogeochemical and ecosystem relevance like Chlorophyll a (Chla), optical backscattering or attenuation coefficients which are proxies of Particulate Organic Carbon (POC), Colored Dissolved Organic Matter (CDOM). Thanks to recent algorithmic improvements, new bio-optical variables such as backscattering coefficient or absorption by CDOM, at present can also be extracted from space observations of ocean color. In the future, an intensification of in situ measurements by bio-optical profiling floats would permit the elaboration of unique 3D / 4D bio-optical climatologies, linking surface (remotely detected) properties to their vertical distribution (measured by autonomous platforms), with which key questions in the role of the ocean in climate could be addressed. In this context, the objective of the IOCCG (International Ocean Color Coordinating Group) BIO-Argo working group is to elaborate recommendations in view of a future use of bio-optical profiling floats as part of a network that would include a global array that could be "Argo-relevant" and specific arrays that would have more focused objectives or regional targets. The overall network, realizing true multi-scale sustained observations of global marine biogeochemistry and biooptics, should satisfy the requirements for validation of ocean color remote sensing as well as the needs of a wider community investigating the impact of global change on biogeochemical cycles and ecosystems. Regarding the global profiling float array, the recommendation is that Chla as well as POC should be the key variables to be systematically measured. A first target would be to implement $20 \%$ of the Argo floats with these measurements within a five-year term. The 
yearly additional cost is estimated to $1.5 \mathrm{M} \$$, including additional management structure in each of the two Global Data Assembly Centers.

\section{STATE OF THE ART - SCIENTIFIC OBJECTIVES}

In the context of global change and ocean response to climatic and anthropogenic forcing, it is critical to improve our understanding of, and to reduce the uncertainties in, the estimates of biologically mediated carbon fluxes. At the root of most of the present uncertainties in the carbon budget is the scarcity of data. The ocean is indeed critically undersampled, as nicely summarized by [1]: "if I were to choose a single phrase for the first century of modern oceanography, it would be a century of undersampling". This statement is particularly true for oceanic biological and biogeochemical properties: undersampling is the rule and represents the main cause for our limitation in understanding and quantifying the key processes at play in the ocean carbon cycle. In particular these processes occur over a continuum of spatial and temporal scales some of which (e.g. mesoscale, "event" scale, seasonal scale) are determinant in driving the magnitude of the biogeochemical fluxes. In parallel to these critical scales, our current understanding mostly relies on shipbased observations and a few time series observations at several locations. A large part of the known variability in oceanic biological processes is based on poor spatiotemporal coverage.

This pessimistic view of biogeochemical sampling is nevertheless changing. Since the past two decades, and particularly since the beginning of the SeaWiFS (Seaviewing Wide Field of View Sensor) satellite era in 1997, remote sensing of ocean colour has become a unique tool by which biologists and biogeochemists have access to quasi-synoptical measurements of the surface Chla concentration, an essential proxy for phytoplankton biomass. The use of ocean colour remote sensing made it possible to address processes ranging from meso-scale [2] to inter-annual and decennial variability [3]. More recently, thanks to the development of new algorithms, additional fundamental biogeochemical quantities have begun to be derived from space, like POC [4], CDOM [5], indices of particle size [6] or the phytoplankton community composition [7 and 8]. New perspectives are opening in the understanding of biogeochemical cycling at the regional and global scales by using the new remotelydetected products.

These observation techniques, however, also have their own inherent limitations. First, remotely sensed products are not direct measurements but quantities derived through models so that in situ data are essential to validate inversion algorithms. Secondly, and very importantly, as satellites only "see" the upper $20 \%$ of the euphotic zone, they miss the important processes and variables involved in carbon fluxes in the ocean interior. The extension of the surface properties down to the deeper layers is a critical issue that requires the development of a capacity for intensive in situ measurements within the water column.

The profiling floats of the Argo array were initially designed for physical oceanography and hydrography only [9]. They now also represent a potential promising technology for future observations in oceanic biogeochemistry and recent investigations have demonstrated the feasibility as well as the potential of this approach [10, 11, 12, 13, 14 and 15]. Indeed, new generations of chemical, optical and biological miniature, low consumption sensors have been developed and still are being developed. Implemented on these new platforms, including gliders [16], they would allow repeated high-resolution observations of several bio-variables already measured by the satellites.

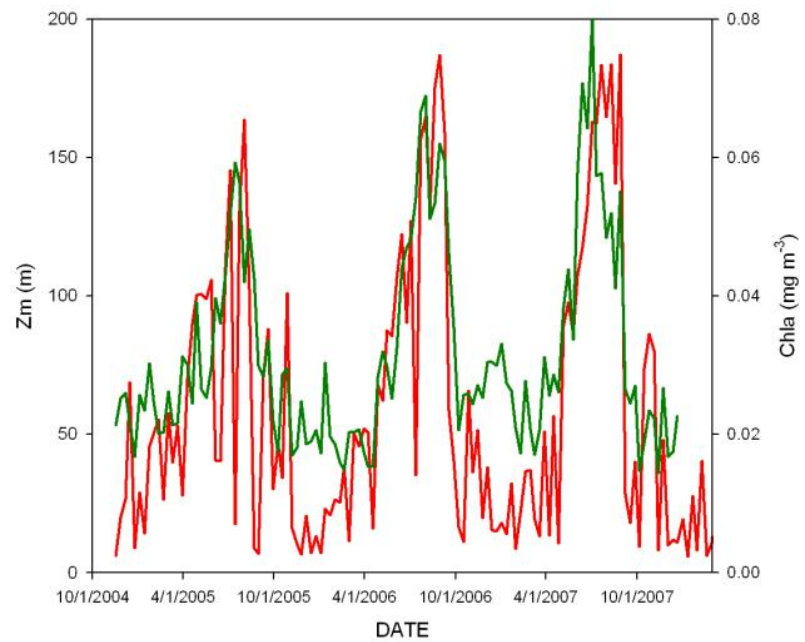

Figure 1. Dynamics of algal biomass as a function of physical forcing in the center of the South Pacific Gyre.

In the most oligotrophic waters of the open ocean, a seasonality in surface Chla concentration (green line), as quantified by SeaWiFS (Sea-viewing Wide Field of

View Sensor), is observed: winter values exceed

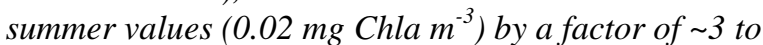

4. The analysis of the TS data from an Argo float deployed in this area at the same period shows a clear cycle in mixed layer thickness (red line). This comparison highlights the process of winter mixing that erodes the deep nutricline, allowing phytoplankton growth limitation to be alleviated and biomass to increase in these clear waters. After Claustre (unpublished results)

The potential of combining Argo float technology together with ocean color observation can be demonstrated with "simple" TS floats (Fig. 1). Thanks to two independent datasets (SeaWiFS (Sea-viewing Wide Field of View Sensor) and Argo), which are 
openly available in quasi real time, such analysis is feasible. This example is a foretaste of the potential in developing synergetic association of remote sensing of ocean color (with additional products than the sole Chla) together with profiling float (with additional biogeochemical profiles to the "standard" TS ones). The present paper thus gives several guidelines in view of developing, in the near future, synergetic capabilities for observing oceanic biogeochemistry through these remotely operated platforms.

\section{WHAT TYPE OF BIO-OPTICAL FLOATS FOR WHAT TYPE OF MISSION?}

At the moment, we recommend the development of three main types of bio-optical floats each of them having very specific and targeted objectives.

\subsection{The "BIO-Argo" float.}

The rationale for the development of such floats is to provide the biogeochemical community with an unprecedented amount of vertical profiles of (real-time) key biogeochemical and bio-optical variables. This objective would be achieved by developing a generic, low cost, low consumption bio-optical / biogeochemical payload that would be disseminated through the Argo network and take advantage of an existing infrastructure. The proof-of-concept of this float has been described in [13] (Fig. 2). In this paper, a 3-year time series of Chl $a$ and backscattering (a proxy for POC) was acquired in the North Atlantic using an APEX (Autonomous Profiling Explorer) float equipped with an optical sensor. The data complements the synoptic description of surface characteristic by ocean color sensors by providing the vertical dimension.

Other floats equipped with similar sensors (and additional ones) are presently operating in other parts of the global ocean like the South and North Pacific subtropical gyres or various sites in the Mediterranean Sea (see http://www.obsvlfr.fr/OAO/provbio/summary.html). They are presently used in association with merged ocean color data of MERIS (Medium Resolution Imaging Spectrometer), MODIS (Moderate Resolution Imaging Spectroradiometer) and SeaWiFS (see http://www.globcolour.info/).

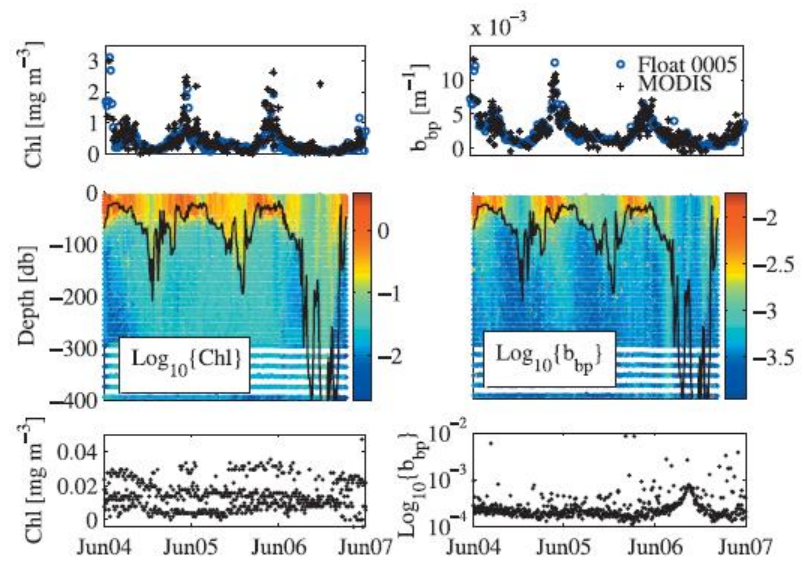

Figure 2. Satellite retrievals of Chla and particulate backscattering (top panels), near-surface in-water distributions of particulate backscattering and Chla (middle panels) and Chla and backscattering values below 950m measured by a profiling float during three years in which it roved in the North Atlantic (from Boss et al., 2008, EOS (Earth Observing System)). At the end of 2006, the increase in backscattering at depth was associated to the float being trapped in an eddy. The signature of the eddy was not discernable in surface data.

The fluorescence of Chla (proxy of Chla concentration) and the backscattering coefficient (proxy of POC) are the top priority bio-optical measurements to be performed as part of this network. Both variables are retrieved from space and represent essential stock variables for quantifying total phytoplankton biomass as well as total organic biomass. Besides providing such data in time periods (e.g. Winter high latitudes) and/or locations (e.g. Southern Ocean) that are chronically under-sampled, the dense and continuous data acquisition from a BIO-Argo network would support various scientific or operational activities:

1. The extension of the satellite signal to the ocean interior.

2. The validation of several level 2 and 3 products derived from ocean color measurements [Level 2 corresponds to a geophysical product value (e.g. Chla) for a given pixel; level 3 corresponds to a level 2 product binned over a certain period of time (e.g. day, year)]. 
3. The validation of two main kinds of bio-optical models of primary production either based on Chla [17 and 18] or on phytoplankton carbon [19].

4. The validation of global circulation models coupled to global biogeochemical models with key variables.

5. The data assimilation into (future) global biogeochemical operational models.

6. The extraction of statistical biogeochemical/biooptical trends, with possible applications to climate sciences, from the generated dense databases.

7. The identification of pattern processes in the ocean interior missed by ocean color.

\subsubsection{Type of mission:}

This mission would have to strictly adhere to Argo rules, i.e. profiling every 10 days. The sensors should be certified down to $2000 \mathrm{~m}$. While such types of float can be operated using ARGOS telemetry [13], iridium telemetry, allowing meter scale resolution should be the preferred solution and would likely represent an additional improvement for the Argo data acquisition.

Note that these bio-optical measurements could be combined with $\mathrm{O}_{2}$ measurements [12] allowing a BIOArgo float to serve the needs of a wider bio-optical and bio-geochemical community with a small-added expense in terms of cost and energy.

2.1.2 Sizing an array, additional costs and associated infrastructure

A desirable first target would be to have $20 \%$ of the Argo array (600 floats) with the capacity to measure Chl $a$ as well as optically resolved POC within 5 years. The implementation of such array could be envisaged has part a large pilot study in a climate-sensitive area. The hardware additional cost (calibrated sensor plus iridium antenna) is $\sim 6-7 \mathrm{k}$. The iridium telemetry being much faster than ARGOS, the reduction in transmission time using iridium partly compensates for additional energy consumption by the optical sensor. A reasonable profile number for such a float is $\sim 200$ for a life-time of $\sim 5$ years. This means that $\sim 120$ Bio-Argo floats have to be re-launched each year. Taking into consideration a $20 \%$ energy loss with respect to a standard TS Argo float with ARGOS telemetry $(\sim 3 \mathrm{~K} \$)$ a transmission cost of $2 \mathrm{~K} \$\left(10 \$\right.$ profile $\left.^{-1}\right)$, the total additional cost (hardware, transmission, extra energy consumption) is $\sim 12 \mathrm{~K} \$$. The yearly cost of such additional measurements to the Argo array would be $1.5 \mathrm{M} \$ /$ year.

The associated resources with respect to data management and real-time quality control (QC) are estimated to one person in each of the Global Data Assembly Center. Additional human resources will also be required to deliver to the community, real and delayed mode data of full 3D/4D pictures of these biovariables, merging the synoptical surface field of ocean color to the in situ measurement of the ocean interior (see Sect. 3).

\subsection{The Carbon-float}

The proof-of-concept of the carbon-float has been recently described in [15 and 20]. Basically, this float is dedicated to process studies aiming at investigating in details key stocks and fluxes involved in the carbon cycle. It will have primarily the capability to optically monitor POC and PIC (particulate inorganic carbon) as well as Net community production and exportation flux (Fig. 3). Additionally the composition of the settling material (POC vs PIC) could be also optically resolved as well as other measurements (e.g. Chl $a$ fluorescence) that could be implemented on this "flexible" float.

Due to the amount of data to transfer, the iridium telemetry is obviously mandatory. It will also allow adaptative sampling to be conducted over a continuum of temporal scale ranging from the diel one (and allowing production rates to be estimated [21 and 22]) to the seasonal scale [15]. Thanks to iridium, an end-ofmission and surfacing command can be sent to this float allowing its retrieval in the particular case where it is deployed in the context of "classical" cruises or even when dedicated recovery cruises are planned.

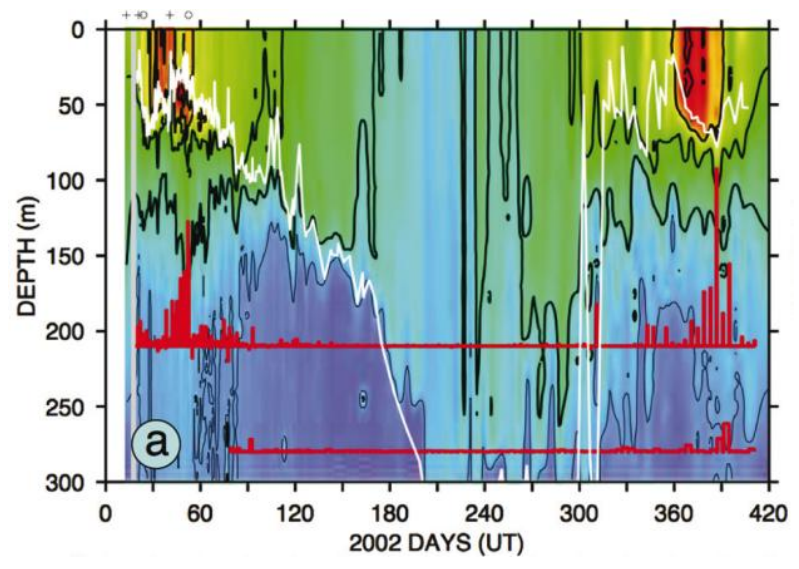

Figure 3. Time series of particulate organic concentration (color plot) and particle flux (red bars, in relative units) in the Southern ocean (around $55^{\circ} \mathrm{S}$, $\left.170^{\circ} \mathrm{W}\right)$. The data were acquired by the Carbon Explorer float, which associates a Solo float to a suite of optical sensors. The reduction of the mixed layer (white line) in spring allows the increase in POC resulting from the development of the phytoplankton bloom, and the subsequent increase of particulate material export of at depth. From Bishop and Wood (2009).

This float will be operated independently of the Argo array. Nevertheless part of its measurements will be similar to those realized by the Bio-Argo float (e.g. 
optically-resolved POC, possibly Chla). The acquired data will necessarily have to be implemented (and in conformity with the established quality control procedures) in the large database that will be subsequently set as part of a global Bio-Argo array.

\subsubsection{Sizing an array of Carbon-floats and associated costs.}

During a 5-year term, an array of 20-40 operational carbon floats deployed in key and undersampled areas (e.g. North Pacific and Atlantic, Southern Ocean), in complement to the wider and coarser spatial resolution of the global array is a reasonable objective. A basic estimation of the associated cost (float plus sensors and devices) is $1-2 \mathrm{M} \$$.

\subsection{The VAL-float}

The primary objective of a Val-float will be to acquire data dedicated to the validation of ocean color-based algorithms. The VAL-floats will collect accurate and frequent profiles of radiometric and associated biogeochemical data concurrent to ocean color satellite overpasses. These floats will be operated as part of an array that will allow satellite seatruths to be acquired globally. Given the very specific objectives of CALVAL (Calibration/Validation) mission and the considerable differences to the standard Argo mission, this array will be operated independently, but, as for the Carbon-float, part of the measurements will be implemented in a global data set. The VAL-float will thus measure in priority down-welling irradiance (Ed) and up-welling radiance ( $\mathrm{Lu})$ associated with $\mathrm{Chl} a$ fluorescence and backscattering coefficient. Ed and $\mathrm{Lu}$ measurements will be acquired either by multispectral radiometers with at least 6 wavelengths (410, 440490 , $555665,750 \mathrm{~nm})$ or ideally by hyperspectral radiometers. These sensors will be positioned at the end of light arms extending away from the float, minimizing shading by the float or antenna. Additional measurements include CDOM fluorescence and a second backscattering channel, allowing the spectral dependency of backscattering to be derived.

Maximizing validation matches with remotely sensed ocean color is the principal mission driver so that the two-way iridium communication allowing adaptative sampling strategy is essential to develop a cost-effective approach, i.e. performing the largest number of good matchups during the float lifetime. In particular, sampling strategy will be adapted taking into consideration forecasted cloud conditions. For sunny days, float-surfacing time will be phased with respect to the time of satellite overpasses and replicates will be performed. For cloudy days sampling could be relaxed. Iridium is also mandatory for transmission of the large amount of data that will be acquired considering that (1) high vertical resolution is required $(\sim 10 \mathrm{~cm}$ scale for radiometry) and (2) multispectral if not hyperspectral data will be acquired.

This mission is critical because current databases used in algorithm development include data that are geographically and temporally limited, possibly biasing existing ocean color inversion algorithms. In this context the VAL-float appears totally complementary to dedicated CAL-VAL moorings in the open ocean (e.g. MOBY (MArine Optical BuoY) in the sub-tropical North Pacific, BOUSSOLE (BOUée pour l'acquiSition de Séries Optiques à Long termE) in the Northwestern Mediterranean Sea), which deliver more complete and essential data for the vicarious calibration of remote OCR (ocean colour radiometry) sensors.

\subsubsection{Sizing an array of VAL-floats and associated} costs.

Within a 5-year term, an array of 20-40 VAL operational floats deployed in various trophic oceanic regimes (to cover the range of color seen by the satellite) is a reasonable target. Such floats would have available energy for $\sim 200$ profiles allowing 2 years of acquisition (one matchup every 3-4 days). The cost of a float, including telemetry and a very complete set of sensors is $\sim 75 \mathrm{k} \$$. A yearly replacement of $25 \%$ of the array (considering that an additional $25 \%$ can be retrieved through recovery cruises thanks to iridium telemetry) make the total amount around 0.4-0.80 M\$ year $^{-1}$. Two persons full time would be required in the process of deployment, data treatment and QC procedure.

\section{EXTENDING THE REMOTELY-DETECTED SIGNAL TO THE OCEAN INTERIOR}

One of the most significant contributions of a biooptical profiling float array will likely be the ability to provide routine depth-resolved bio-optical and geophysical data at low cost from which the development of climatologies will be an essential outcome. These climatologies are indeed strongly required for many diverse scientific applications, ranging, for example, from bio-optical modeling of primary production [17] to the identification and understanding of long term trends in biogeochemical properties [3], or to the modeling of coupled ecosystem / biogeochemical cycling of elements at global scale [23 and 24]. Developing a 3D/4D biogeochemical description of the ocean is certainly challenging but this can be likely achieved by developing synergies between the two remotely-operated techniques, the space-based and the in situ ones. The prerequisite is to elaborate dense databases from which the relationship between vertical distribution of a certain variable and its surface signature can be established, analyzed and further modeled using appropriate parameterization. 
It is here proposed that Chla concentration and optically-derived POC, both variables being accessible from space, become core measurements acquired by any of the three classes of bio-optical floats. Considering the sizing of the various arrays described above, BIO-Argo, Carbon- and Val- floats would yearly acquire about 20,000, 3,000 and 3,000 profiles of these bio-variables, respectively. This represents a tremendous amount of data for bio-optical and biogeochemical oceanographers (more than 1,000 days of ship-based acquisition would be required to collect such data!). For Chla, methods already exist allowing the inference of the water column vertical distribution from its remotely sensed surface values [8 and 25]. However, the databases on which these empirical methods are based consist of discrete measurements that do not have the same spatiotemporal coverage (only a few thousand profiles for references mentioned above) as the hydrological databases (e.g. Levitus climatology; in 2008 the Argo program collected $\sim 130,000 \mathrm{TS}$ profiles). Thus, an array of bio-optical floats would rapidly provide the data required to support the refinement of the previous parameterization for Chla and would allow parameterizations dedicated to POC vertical distribution to be developed.

Additionally, besides Chl $a$ and POC, a dedicated acquisition and archiving effort also needs to be undertaken for "new" variables accessible or derivable from remote sensing (e.g., diffuse attenuation coefficient, absorption coefficient, particle size index and production rates). This effort has to be started as soon as possible (from past and current measurements performed by VAL- and Carbon-floats) with the goal to develop, in the mid-term, parameterizations of the vertical distribution of these variables, similarly to those developed for Chl $a$ and POC.

\section{THE CHALLENGE OF PRODUCING LONG- TERM COHERENT DATASETS.}

Recent studies have highlighted the mid-to long-term evolution of surface phytoplankton in the global ocean from the analysis of the SeaWiFS time series of ocean color data for 1997-2006 [26] or by comparing CZCS (1979-1983) to SeaWiFS data [3 and 27]. Such analyses were made possible because (1) satellite time series were made self consistent thanks to evaluation of sensor performances over its lifetime and development of appropriate corrections and (2) methods have developed for a somewhat unified data-reprocessing when data from two [3] or three [28] satellites were used.

One of the long-term goals of deploying bio-optical floats is to acquire databases having the quality required to address climate-relevant issues in marine biogeochemistry and ecosystem functioning. Therefore the issue of ensuring data quality over a long term basis has to be anticipated at the same time that certain projects relying on the use of floats are starting. This requires developing new calibration procedures adapted to the specificity of the platform with respect to its deployment and to data collection missions performed over several years. This point will deserve particular attention with respect to fluorescence measurements of Chla. This requires development of quality control procedures that guarantee the consistency of data generated by various sensors and platforms. The scientific success of an array of bio-optical floats and its synergetic combination with ocean color remote sensing and modeling will strongly rely on the effort that our community will dedicate to this critical issue.

\section{ADDITIONAL INFORMATION.}

The BIO-Argo working group is sponsored by IOCCG. The composition as well as the terms of references of this group can be viewed at: http://www.ioccg.org/groups/argo.html.

\section{REFERENCES}

1. Munk, W. M. 2000. Oceanography before, and after, the advent of satellites, p. 1-4. In D. Halpern [ed.], Satellites, oceanography and society. Elsevier.

2. Doney, S. C., Glover, D. M., Mccue, S. J. \& Fuentes M. (2003). Mesoscale variability of Sea-viewing Wide Fieldof-view Sensor (SeaWiFS) satellite ocean color: Global patterns and spatial scales. Journal of Geophysical Research, 108, 3024, doi:10.1029/2001JC000843

3. Antoine, D., Morel, A., Gordon, H.R., Banzon, V.F. \& Evans R.H. (2005). Bridging ocean color observations of the 1980's and 2000's in search of long-term trends. Journal of Geophysical Research, 110, C06009, doi:10.1029/2004JC002620.

4. Stramski, D. \& others (2008). Relationships between the surface concentration of particulate organic carbon and optical properties in the eastern South Pacific and eastern Atlantic Oceans. Biogeosciences, 5, 171-201.

5. Siegel, D. A., Maritorena, S., Nelson, N. B., Hansell, D. A. \& Lorenzi-Kayser M. (2002). Global distribution and dynamics of colored dissolved and detrital organic materials. Journal of Geophysical Research, 107, 3228, doi:10.1029/2001JC000965.

6. Loisel, H., Nicolas, J. M., Sciandra, A., Stramski, D. \& Poteau A. (2006). Spectral dependency of optical backscattering by marine particles from satellite remote sensing of the global ocean. Journal of Geophysical Research, 111, C09024, doi:10.1029/2005JC003367.

7. Alvain, S., Moulin, C., Dandonneau, Y. \& Breon F. M. (2005). Remote sensing of phytoplankton groups in case 1 waters from global SeaWiFS imagery. Deep Sea Research I, 52, 1989-2004.

8. Uitz, J., Claustre, H., Morel, A., \& Hooker, S. (2006). Vertical distribution of phytoplankton communities in open ocean: an assessment based on surface chlorophyll. 
Journal of Geophysical Research, 111, C08005, doi:10.1029/2005JC003207.

9. Freeland, H. \& Co-Authors (2010)."Argo - A Decade of Progress" in these proceedings (Vol. 2), doi:10.5270/OceanObs09.cwp.32.

10. Bishop, J. K. B., Wood, T. J., Davis, R. E. \& Sherman J. T. (2004). Robotic Observations of Enhanced Carbon Biomass and Export at $55^{\circ} \mathrm{S}$ During SOFeX, Science, 304, 417-420.

11. Kortzinger, A., Schimanski, J., Send, U. \& Wallace D. (2004). The Ocean Takes a Deep Breath, Science 306, 1337-.

12. Gruber, N. \& Co-Authors (2010). "Adding Oxygen to Argo: Developing a Global In Situ Observatory for Ocean Deoxygenation and Biogeochemistry" in these proceedings (Vol. 2), doi:10.5270/OceanObs09.cwp.39.

13. Boss, E., Swift, D., Taylor, L., Brickley, P., Zaneveld, R., Riser, S., Perry, M. J. \& Strutton, P. G. (2008). Observations of pigment and particle distributions in the western North Atlantic from an autonomous float and ocean color satellite. Limnology and Oceanography, 53, 2112-2122.

14. Riser, S. C., \& Johnson K. S. (2008). Net production of oxygen in the subtropical ocean. Nature, 451, 323-325.

15. Bishop, J. K. B., \& Wood T. J. (2009). Year-round observations of carbon biomass and flux variability in the Southern Ocean. Global Biogeochemical Cycles, 23, GB2019, doi:10.1029/2008GB003206.

16. Testor, P. \& Co-Authors (2010). "Gliders as a Component of Future Observing Systems" in these proceedings (Vol. 2), doi:10.5270/OceanObs09.cwp.89.

17. Antoine, D., André, J. M. \& Morel A. (1996). Oceanic primary production 2 . Estimation at global scale from satellite (coastal zone color scanner) chlorophyll. Global Biogeochemical Cycles, 10, 57-69.

18. Behrenfeld, M. J., \& Falkowski P. G. (1997). Photosynthetic rates derived from satellite-based chlorophyll concentration. Limnology and Oceanography, 42, 1-20.

19. Behrenfeld, M. J., Boss, E., Siegel, D. A., \& Shea, D. M. (2005). Carbon-based ocean productivity and phytoplankton physiology from space. Global Biogeochemical Cycles, 19, GB1006, doi:10.1029/2004GB002299.

20. Bishop, J. K. B. (2009). Autonomous observations of the ocean biological carbon pump. Oceanography, 22, 182193.

21. Bishop, J. K. B., Davis, R. E., \& Sherman, J. T. (2002). Robotic observation of dust storm enhancement of carbon biomass in the North Pacific. Science, 298, 817821.

22. Claustre, H., Huot, Y., Obernosterer, I., Gentili, B., Tailliez, D. \& Lewis, M. R. (2008). Gross community production and metabolic balance in the South Pacific Gyre, using a non intrusive bio-optical method. Biogeosciences, 4, 463-474.
23. Le Quéré, C. \& others (2005). Ecosystem dynamics based on plankton functional types for global ocean biogeochemistry models, Global Change Biology, 11, 2016-2040, doi:10.1111/j.1365-2486.2005.1004.x

24. Le Quéré, C. \& Co-Authors (2010). "Observational Needs of Dynamic Green Ocean Models" in these proceedings (Vol. 2), doi:10.5270/OceanObs09.cwp.56.

25. Westberry, T., Behrenfeld, M. J., Siegel, D. A., \& Boss, E. (2008). Carbon-based primary productivity modeling with vertically resolved photoacclimation, Global Biogeochemical Cycle, 22, GB2024, 10 doi:10.1029/2007gb003078, 2008.

26. Behrenfeld, M. J. \& others (2006) Climate-driven trends in contemporary ocean productivity, Nature, 444,752 755.

27. Gregg, M. C. \& Conkright, M. A. (2002). Decadal change in global ocean chlorophyll. Geophysical Research Letters, 29, doi:10.1029/2002GL014689.

28. Mangin, A. \& Co-Authors (2010). "Exploitation of GlobColour dataset: global characterisation of Chlorophyll, aCDM and bbp uncertainties at pixel level" in these proceedings (Annex), doi:10.5270/OceanObs09. 